\title{
An adaptive neuro fuzzy inference system controlled space cector pulse width modulation based HVDC light transmission system under AC fault conditions
}

M. Ajay Kumar $^{1 *}$, N. V. Srikanth ${ }^{1}$

1 Electrical Engineering Department, National Institute of Technology Warangal, AP, India-506004

Received 14 August 2013; accepted 17 December 2013

\begin{abstract}
In HVDC Light transmission systems, converter control is one of the major fields of present day research works. In this paper, fuzzy logic controller is utilized for controlling both the converters of the space vector pulse width modulation (SVPWM) based HVDC Light transmission systems. Due to its complexity in the rule base formation, an intelligent controller known as adaptive neuro fuzzy inference system (ANFIS) controller is also introduced in this paper. The proposed ANFIS controller changes the PI gains automatically for different operating conditions. A hybrid learning method which combines and exploits the best features of both the back propagation algorithm and least square estimation method is used to train the 5-layer ANFIS controller. The performance of the proposed ANFIS controller is compared and validated with the fuzzy logic controller and also with the fixed gain conventional $\mathrm{PI}$ controller. The simulations are carried out in the MATLAB/SIMULINK environment. The results reveal that the proposed ANFIS controller is reducing power fluctuations at both the converters. It also improves the dynamic performance of the test power system effectively when tested for various ac fault conditions.
\end{abstract}

Keywords: HVDC Light; space vector PWM • fuzzy logic • neural network • adaptive neuro fuzzy inference system (c) Versita sp. z o.o.

\section{Introduction}

With recent development of power electronics technology, HVDC technology utilizes voltage source converters (VSC) with self-commutating IGBT converter valves and this technology is commercially named as "HVDC Light" transmission system [1, 2]. It has several benefits over Conventional HVDC such as; rapid and independent control of active and reactive power, reduced voltage dip and waveform distortions on the AC network,

*E-mail: ajaykumar.nitw@gmail.com black-start capability and also strong environmental benefits $[3,4]$. Because of its tremendous benefits, HVDC Light system finds elegant solution in many areas like, remote renewable energy sources, deep-sea crossings, offshore wind farms, power supply to the islands and interconnecting networks [5-7].

In the HVDC Light transmission systems, it is very essential to control dc voltage and power flows of the converter stations. A plethora of publications existed in the literature associated with control algorithms of an HVDC Light system. In [8], a nonlinear control strategy was implemented to enhance the stability of an HVDC Light system. In [9], the authors have presented the performance of VSC-HVDC Light system 
supplied industrial system having on-site generation with frequency control. Conventional VSC control of the HVDC Light system utilizes a nested-loop $d-q$ vector controlled approach based on the linear PI technology [10]. Due to the poor performance of the conventional vector control approach [11], an optimal control scheme based on direct current vector control technique has been proposed [12] for an HVDC Light system for the purposes of improving the performance, stability and reliability of HVDC transmission. Recently, Space vector pulse width modulation (SVPWM) scheme is utilized in the vector controlled HVDC Light system under different short circuit fault conditions [13] to achieve better dc bus utilization and for improving power quality. But, the conventional $\mathrm{PI}$ controllers used in both the converters are unable to change their gains automatically when a perturbation occurs, and also the nonlinear behavior showed by the converters, a fuzzy logic controller is introduced in this paper to suppress the power oscillations; thereby it improves the stability and overall system performance [14]. Fuzzy logic controllers are superior to the conventional PI controllers, particularly for nonlinear systems such as HVDC Light systems. It doesn't depend on the detailed system modeling and is robust to different operating conditions [15]. Although, it is a fast approach for uncertain problems, it requires a good knowledge and experience of operators working on the system and also not guaranteed that rules are coherent [16]. The main goal of this paper is to develop a control scheme of an HVDC Light transmission system by incorporating an adaptive neuro fuzzy inference system (ANFIS) controller [17] in order to overcome aforementioned drawbacks and also to damp out the power oscillations at both the converter stations. The internal structure and learning algorithm of ANFIS was described in [18]. ANFIS is an adaptive and robust method since it combines the benefits of artificial neural networks and fuzzy logic controller. Moreover, it has a good learning capability and nonlinear ability [19]. The rest of this paper is presented as follows: Section 2 explains the detailed mathematical modeling of the HVDC Light converter station. In Section 3, the proposed controllers are clearly explained. Section 4 provides simulation and result analysis of different controllers under AC fault conditions. Finally, Section 6 concludes the performance of the ANFIS PI controlled SVPWM based HVDC Light transmission system.

\section{Mathematical Modelling}

A schematic diagram of an HVDC Light transmission system is shown in Figure 1. Both of the converter stations in the HVDC Light system are connected to the $A C$ network via line resistor $R$, phase reactor $L$ and a DC capacitor $C$ is in parallel with the DC bus of the station. One can write the equations in the $d-q$ synchronous frame by applying $\mathrm{KVL}$ across the source and converter $[12,13]$ :

$$
\begin{aligned}
& V_{s d}-V_{c d}=L \frac{d i_{d}}{d t}+R i_{d}+\omega L i_{q} \\
& V_{s q}-V_{c q}=L \frac{d i_{q}}{d t}+R i_{q}-\omega L i_{d}
\end{aligned}
$$

where $V_{s d}$ and $V_{s q}$ are source voltages, $i_{d}$ and $i_{q}$ are line currents, $V_{c d}$ and $V_{c q}$ are converter input voltages.

Based on the instantaneous reactive theory, neglecting the losses of the converter and the transformer, the active and reactive power exchanges from the $A C$ end of the $D C$ link are

$$
\begin{aligned}
& P_{a c}=\frac{3}{2}\left(V_{s d} i_{d}+V_{s q} i_{q}\right) \\
& Q_{a c}=\frac{3}{2}\left(V_{s q} i_{q}-V_{s q} i_{d}\right)
\end{aligned}
$$

Set the direction of the source voltage vector as d-axis hence, $V_{s q}=0$. So, one can write the above two equations as:

$$
\begin{aligned}
P_{a c} & =\frac{3}{2} V_{s d} i_{d} \\
Q_{a c} & =\frac{3}{2} V_{s x} i_{q}
\end{aligned}
$$

Since $V_{s d}$ is constant, from the above equations it can be concluded that the active power will be controlled by $i_{d}$, and whole the reactive power will be controlled by $i_{q}$. On the DC side of the converter, DC current and DC power are:

$$
\begin{gathered}
i_{d c}=C \frac{d V_{d c}}{d t}+i_{c} \\
P_{d c}=V_{d c} i_{d c}
\end{gathered}
$$

where $i_{d c}$ is the DC current to be followed by the capacitor, $V_{d c}$ is the DC link voltage and $i_{c}$ is the current on the DC cable. Neglecting the loss of converter, power of $A C$ side equals to the DC side.

$$
\begin{aligned}
P_{a c} & =P_{d c} \\
\frac{3}{2} V_{s d} i_{d} & =V_{d c} i_{d c}
\end{aligned}
$$

In the present case, converters are controlled through SVPWM scheme, where the modulation ratio $m=$ $\sqrt{3} V_{r e f} / V_{d c}$ and $0 \leq m \leq 1$. SVPWM is a new concept for power system applications, and is based on the space vector representation of the voltages on the two phase coordinates. The overall control structure of both the converter stations is identical and controlled parameters are: 


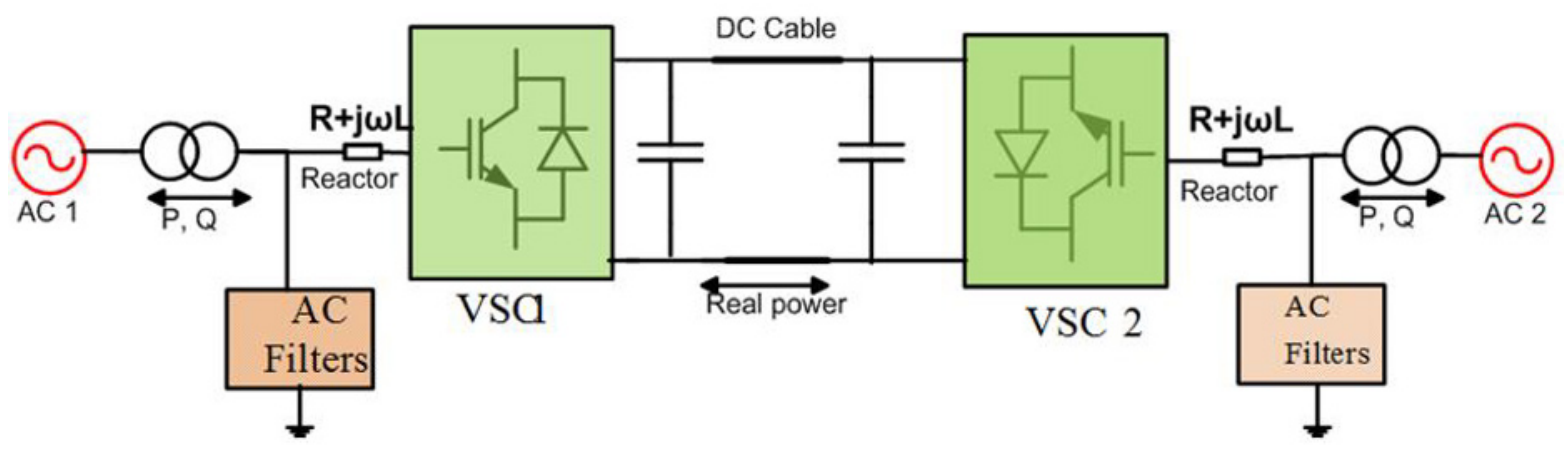

Figure 1. A schematic diagram of an HVDC Light transmission system.

- Active power $(P)$ and reactive power $(Q)$ in station 1.

- DC voltage $\left(V_{d c}\right)$ and reactive power $(Q)$ in station 2.

In PQ control mode, the function of the converter is to regulate active and reactive powers as required. Similarly, in DC voltage and reactive power control mode the converter will maintain the DC voltage as constant and also keep the desired reactive power. Here, instead of conventional PI controllers, a fuzzy logic and ANFIS based PI controllers are proposed to control the parameters. Figure 2 shows the overall structure of the proposed controller.

\section{Proposed method}

\subsection{Fuzzy Controller}

In HVDC Light transmission systems, active and reactive power is controlled by using different types of controllers. In general, conventional PI controllers are used for this application. But, these controllers are designed to work at a particular operating point; any disturbance may cause deterioration of the controller performance. To avoid such a situation, fuzzy $\mathrm{PI}$ controllers are introduced in the HVDC Light transmission systems. In this research work, four PI controllers are used to get faster response and smaller overshoot. Figure 3 shows the inner structure of the fuzzy $\mathrm{Pl}$ controller. The basic fuzzy logic controller is composed of four function blocks as depicted in Figure 3. These are fuzzifier block, knowledge base, inference engine and defuzzifier block. There are two inputs for each of the fuzzy logic controller namely, error (e), change of error (de) and the output known as gain $\left(K_{p}, K_{i}\right)$.

Here, the data of two inputs i.e error and change of error is transformed into linguistic variables by fuzzifier. Then, the linguistic variables are processed by the fuzzy rules in the rule base of the form "If - Then" through fuzzy implication. To fuzzify both input data and output, triangular membership function set is used in this paper with five linguistic variables viz, Negative large (NL), Negative small (NS), zero (Z), Positive small (PS) and Positive large (PL). The membership functions used for the input and output variables in the fuzzy logic tool box are shown in Figure 4. The knowledge base unit has two components, the data base and the rule base. The rule base is shown in the Table 1 , which is dependent on the system. The inference engine executes the inference operations on the rules.

The proposed system will have a total number of 25 fuzzy rules, each one of which is formulated in the "IF -THEN" form like, IF error (e) is NL and change of error (de) is NS, THEN output gain is NL. Here, the controlled output is estimated by the center average method, which can be written as:

$$
\mu^{\text {crisp }}=\frac{\sum_{i}^{n} b_{u} \mu_{i}}{\sum_{i}^{n} \mu_{i}}
$$

where, $\mu_{i}$ - output label for value contributed by the $i^{\text {th }}$ membership function, $b_{i}$ - center of $i^{\text {th }}$ membership function, $n$ - number of contributions from the rules.

\subsection{ANFIS Controller}

ANFIS is an adaptive network that is functionally equivalent to a fuzzy inference system, where the output has been obtained by using fuzzy rules on inputs. Figure 5 
(a)

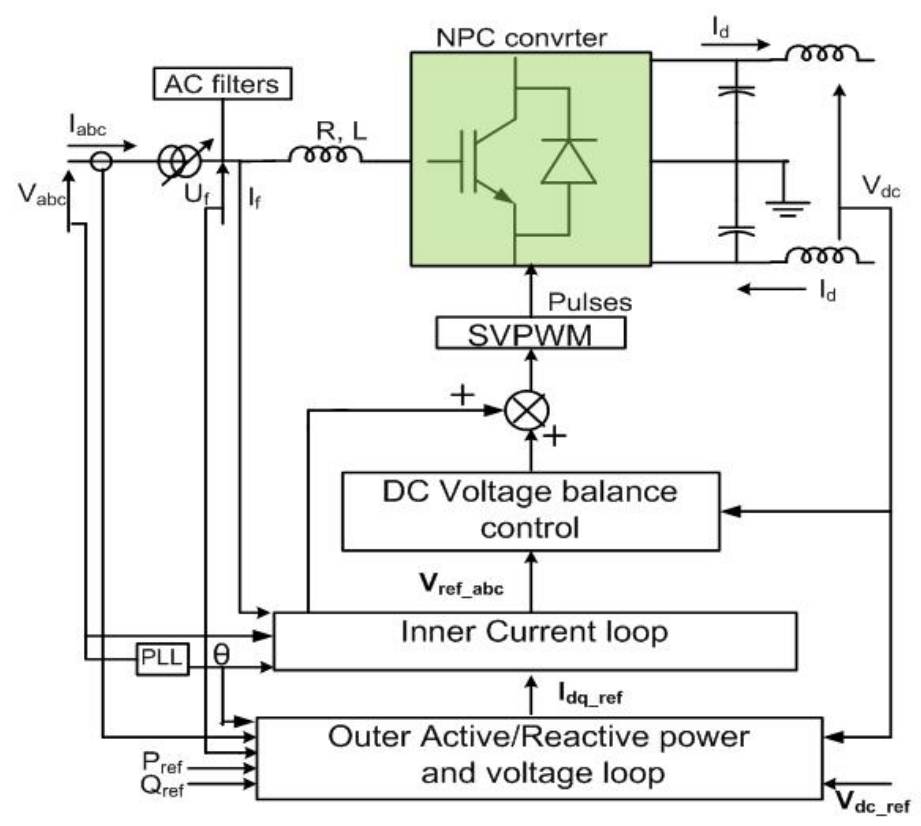

(b)

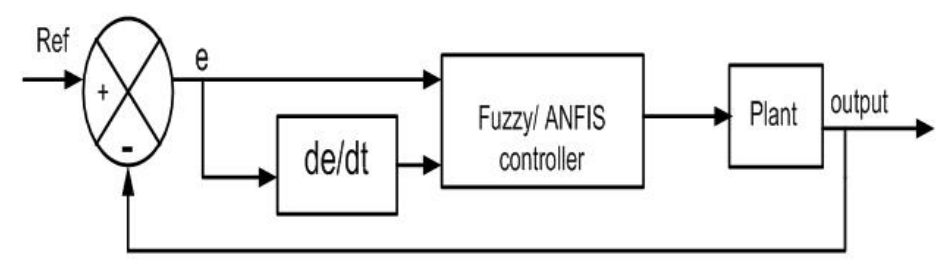

Figure 2. (a) Control structure (b) sub block of inner and outer loops of the proposed controller.

Table 1. Rule base for fuzzy PI controller.

\begin{tabular}{llllll}
\hline $\mathrm{e} \rightarrow$ & $\mathrm{NL}$ & $\mathrm{NS}$ & $\mathrm{Z}$ & $\mathrm{PS}$ & $\mathrm{PL}$ \\
$\mathrm{de} \downarrow$ & $\mathrm{NL}$ & $\mathrm{NL}$ & $\mathrm{NS}$ & $\mathrm{Z}$ & $\mathrm{PS}$ \\
\hline $\mathrm{NL}$ & $\mathrm{NL}$ & $\mathrm{NS}$ & $\mathrm{NS}$ & $\mathrm{NL}$ & $\mathrm{PS}$ \\
$\mathrm{NS}$ & $\mathrm{NS}$ & $\mathrm{NS}$ & $\mathrm{PS}$ & $\mathrm{PS}$ \\
$\mathrm{Z}$ & $\mathrm{Z}$ & $\mathrm{NL}$ & $\mathrm{PS}$ & $\mathrm{PL}$ & $\mathrm{PL}$ \\
$\mathrm{PS}$ & $\mathrm{PS}$ & $\mathrm{PS}$ & & \\
\hline
\end{tabular}




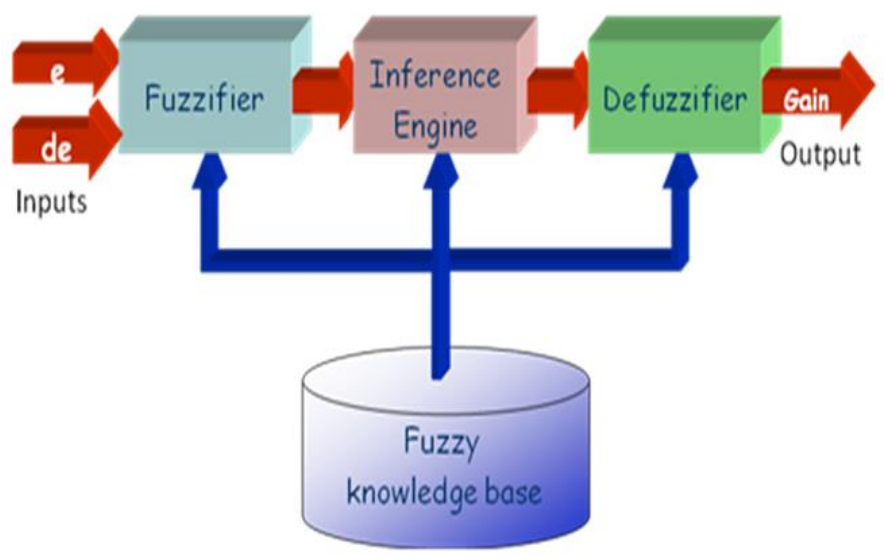

Figure 3. Inner structure of fuzzy logic controller.

depicts a two - input one - output ANFIS structure. The two inputs are $x_{1}$ (error), $x_{2}$ (change of error) and the output is gain. Each input and output variable has five linguistic variables, i.e Negative large (NL), Negative small (NS), Zero (Z), Positive small (PS) and Positive large (PL). Hence, in this proposed ANFIS controller total 25 linguistic variables for the output are employed.

As it was mentioned in Figure 5, the proposed ANFIS architecture consists of five layers wherein circle shaped nodes are called fixed nodes which means the node parameters are independent on the other nodes and square shaped nodes are called adaptive nodes, whose node parameters depend on the other nodes.

\section{Layer 1:}

Number of nodes in this layer represents the number of fuzzy sets used. All the nodes of the first layer are in square shaped and parameters of these nodes defining the membership function. In this research work, a triangular membership function is used as follows:

$$
O_{1 i}=\mu_{A_{i}}\left(x_{1}\right), \quad O_{2 i}=\mu_{B_{i}}\left(x_{2}\right), \quad i=1,2
$$

where $x_{1}$ and $x_{2}$ are the two inputs, $A_{i}$ and $B_{i}$ are the fuzzy sets corresponding to the node $i$. $O_{1 i}$ and $O_{2 i}$ are membership functions of fuzzy set $A_{i}$ and $B_{i}$.

\section{Layer 2:}

In this layer, nodes are known as rule nodes. Each node multiplies the incoming signals and gives the product that represents the weight $\left(w_{i}\right)$ of a rule and is given by

$$
w_{i}=\mu_{A i}\left(x_{1}\right) \mu_{B i}\left(x_{2}\right), \quad i=1,2
$$

Layer 3:

In this layer, weights are normalized as follows:

$$
\overline{w_{i}}=\frac{w_{i}}{w_{1}+w_{2}}, \quad i=1,2
$$

Layer 4:

In general, the dimension of this layer determines the number of fuzzy rules used in the system. For every node of this layer, output is given by

$$
\text { The output }=\bar{w}_{i} f_{1}
$$

where $f_{i}=p_{i} x_{1}+q_{i} x_{2}+r_{i}, \overline{w_{i}}$ is the normalized weight of $i^{\text {th }}$ mode, $p_{i}, q_{i}$ and $r_{i}$ are the designed parameters that are determined during the training process and " $i$ " is the number of membership functions of respective input.

\section{Layer 5}

In the final layer, the overall output is computed by adding all the outputs of the previous layer.

\section{Anfis Training and Testing}

Initially, ANFIS is trained by taking sample data for various faults, i.e. singe phase and three phase short circuit faults at different locations. In the proposed scheme, 900 sets of sample data for different perturbations are taken. The proposed system is checked in MATLAB/ANFIS editor tool box with a triangular membership function as it offers minimum training error. 
(a)

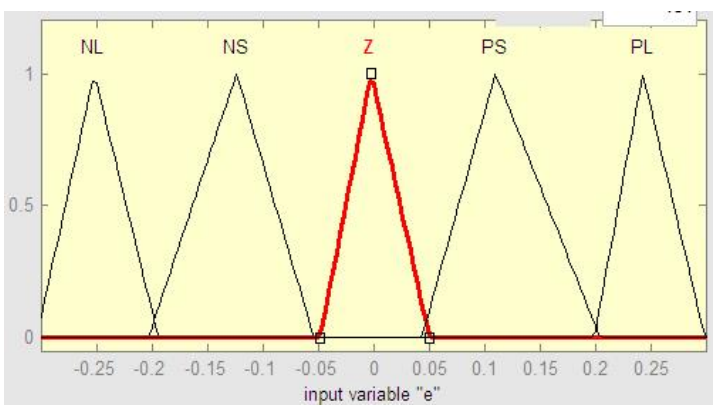

(b)

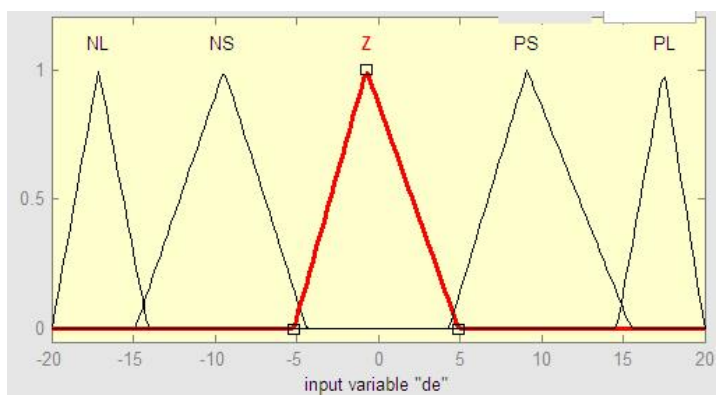

(c)

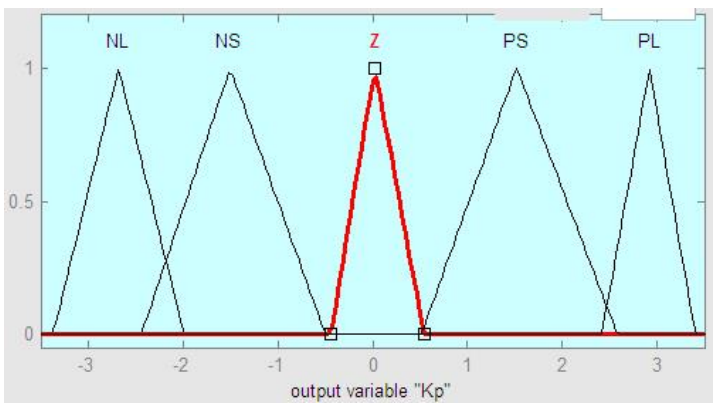

(d)

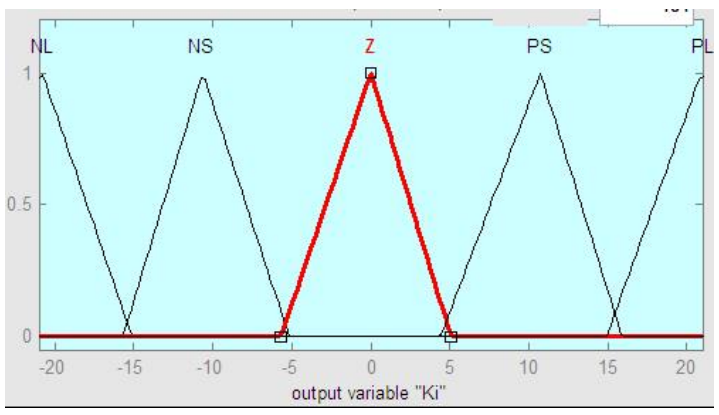

Figure 4. (a) error (b) change of error (c) $K_{p}$; (d) $K_{i}$ membership functions. 


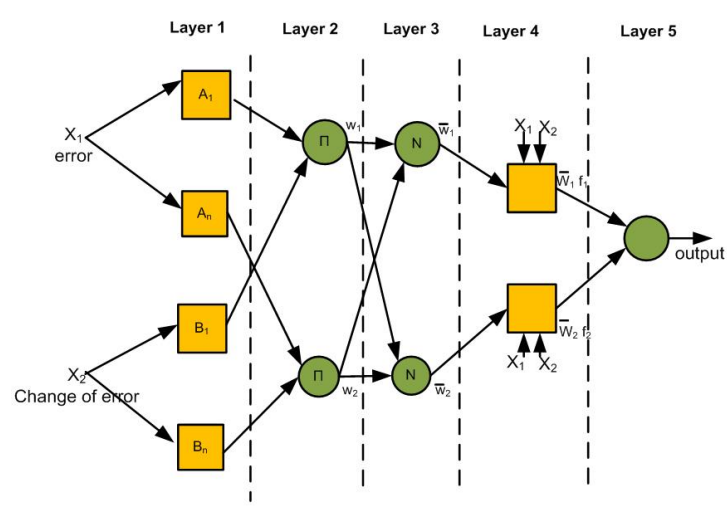

Figure 5. A two-input one-output ANFIS structure.

Table 2. ANFIS parameters.

\begin{tabular}{ll}
\hline Number of nodes & 75 \\
\hline Number of linear parameters & 75 \\
Number of nonlinear parameters & 30 \\
Total number of parameters & 105 \\
Number of training data pairs & 900 \\
Number of testing data pairs & 200 \\
Number of fuzzy rules & 25 \\
\hline
\end{tabular}

Since, the back propagation algorithm is notorious for its slowness and tendency to become trapped in local minima, a hybrid learning algorithm is used in this contribution.

A hybrid learning algorithm combines the backpropagation method and the least square estimation method and hence, it is much faster and accurate in identifying parameters. In the hybrid learning algorithm, least square estimation method identifies the consequent parameters in the forward pass step but in the backward pass step, the error rates propagate backward and the premise parameters are updated by the back propagation algorithm. In order to test the ANFIS controller, 200 pairs of test data is considered with different operating conditions. The detailed parameters of the proposed controller are given in Table 2.

\section{Simulation and results analysis}

In this paper, conventional, fuzzy logic based and ANFIS based space vector PWM controlled HVDC Light transmission systems were simulated in MATLAB/SIMULINK for different AC fault conditions to
Table 3. Parameters of the studied system.

\begin{tabular}{ll}
\hline AC systems: 1 \& 2 & $100 \mathrm{kV}$ \\
\hline Smoothing reactor & $0.0251 \Omega, 8 \mathrm{mH}$ \\
DC line voltage, length & $\pm 100 \mathrm{kV}, 100 \mathrm{~km}$ \\
DC line resistance & $0.0139 \Omega / \mathrm{km}$ \\
DC line inductance & $0.159 \mathrm{mH} / \mathrm{km}$ \\
DC link capacitor & $70 \mu \mathrm{F}$ \\
Switching frequency & $1350 \mathrm{~Hz}$ \\
System frequency & $50 \mathrm{~Hz}$ \\
Base power & $200 \mathrm{MVA}$ \\
\hline
\end{tabular}

study the dynamic performance of the test system and the results were shown in Figure 6 to Figure 9. Here, the limiting values of the gains for all the controllers are the same as in the conventional PI controlled system. The parameters of the test system for carrying the simulation study are described in Table 3. Figure 6 and Figure 8 show the rectifier side active and reactive power responses of an HVDC Light transmission system for a single phase to ground fault, three phase short circuit fault between $1 \mathrm{~s} 1.1 \mathrm{~s}$ at the inverter side AC bus respectively. Similarly, active and reactive powers at the inverter side for the same fault condition are depicted in Figure 7 and Figure 9. From the simulation results, after clearing the fault ANFIS controlled test system was smoothly recovered to its pre-fault condition with smaller peak overshoot compared to the fuzzy and conventional $\mathrm{Pl}$ controller.

\section{Conclusions}

The main contributions of the research work demonstrated in this paper are as follows:

1. The stability improvement of two AC systems connected through a SVPWM based vector controlled HVDC Light transmission system using different intelligent controllers has been presented.

2. Initially, a fuzzy logic controller has been designed to improve the dynamic performance of the studied HVDC Light transmission system.

3. Finally, an ANFIS technology is incorporated with the studied system and simulation study has been carried out to compare the effectiveness of the proposed controller.

4. It can be concluded from the simulation results that the proposed SVPWM based HVDC Light system 
(a)

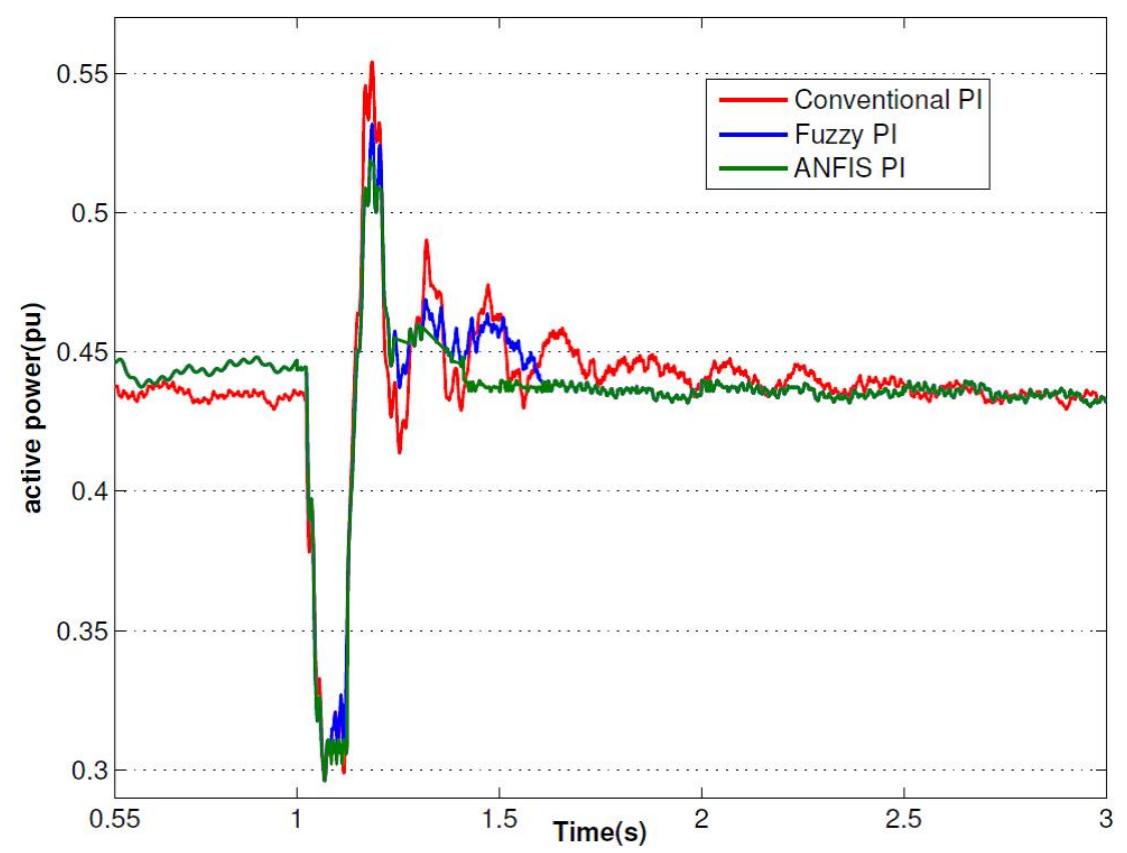

(b)

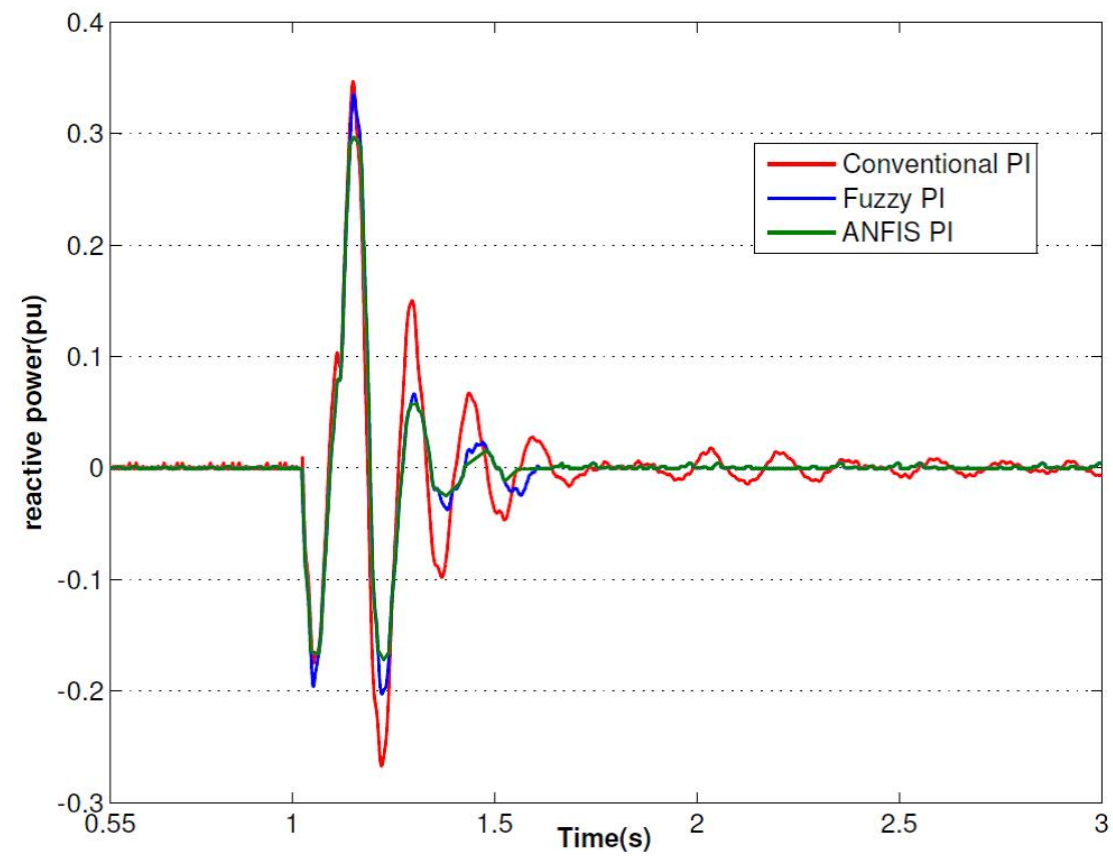

Figure 6. (a) Active power (b) reactive power at rectifier AC bus for a 5 cycle line to ground fault on inverter side AC bus. 
(a)

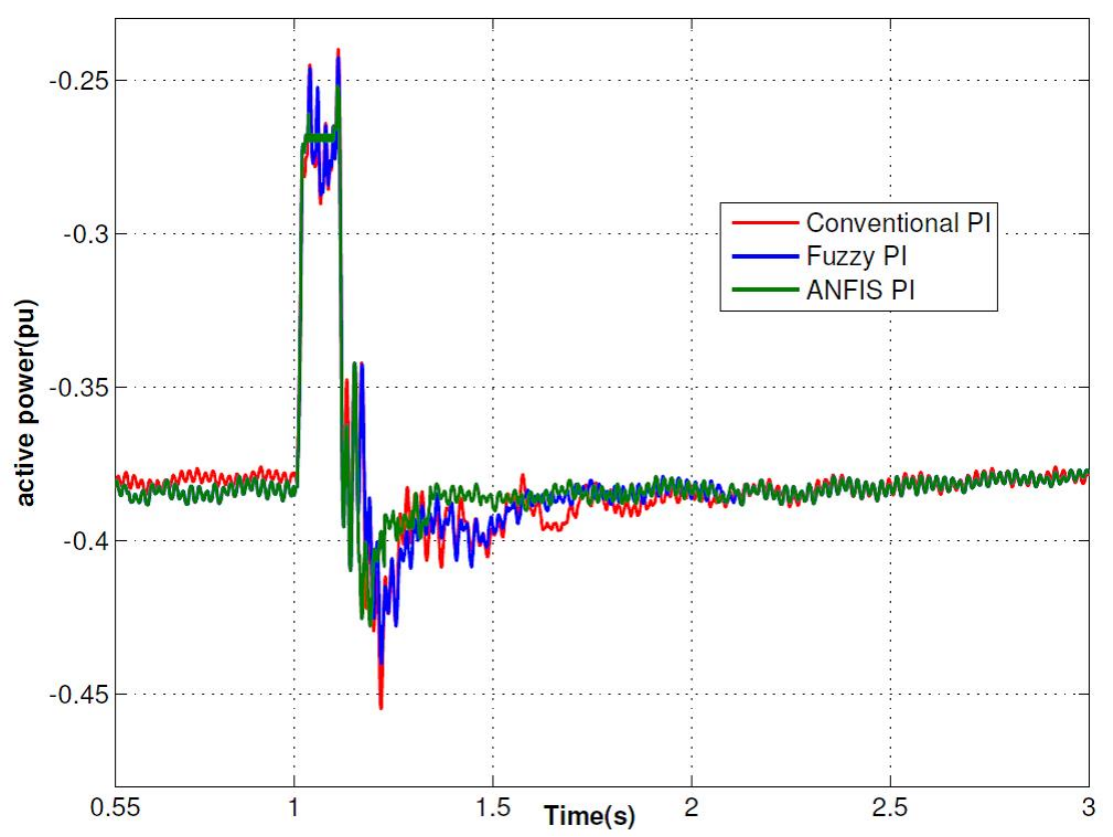

(b)

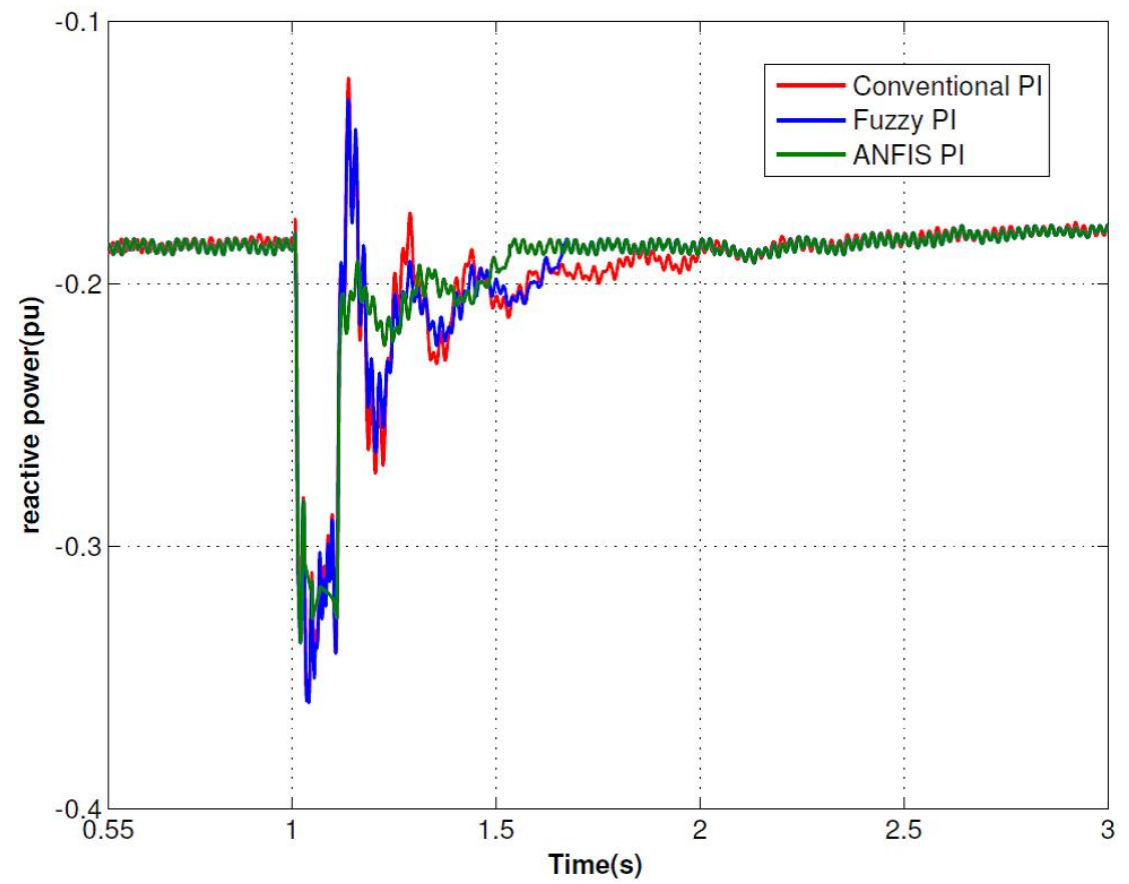

Figure 7. (a) Active power (b) reactive power at inverter AC bus for a 5 cycle line to ground fault on inverter side AC bus. 
(a)

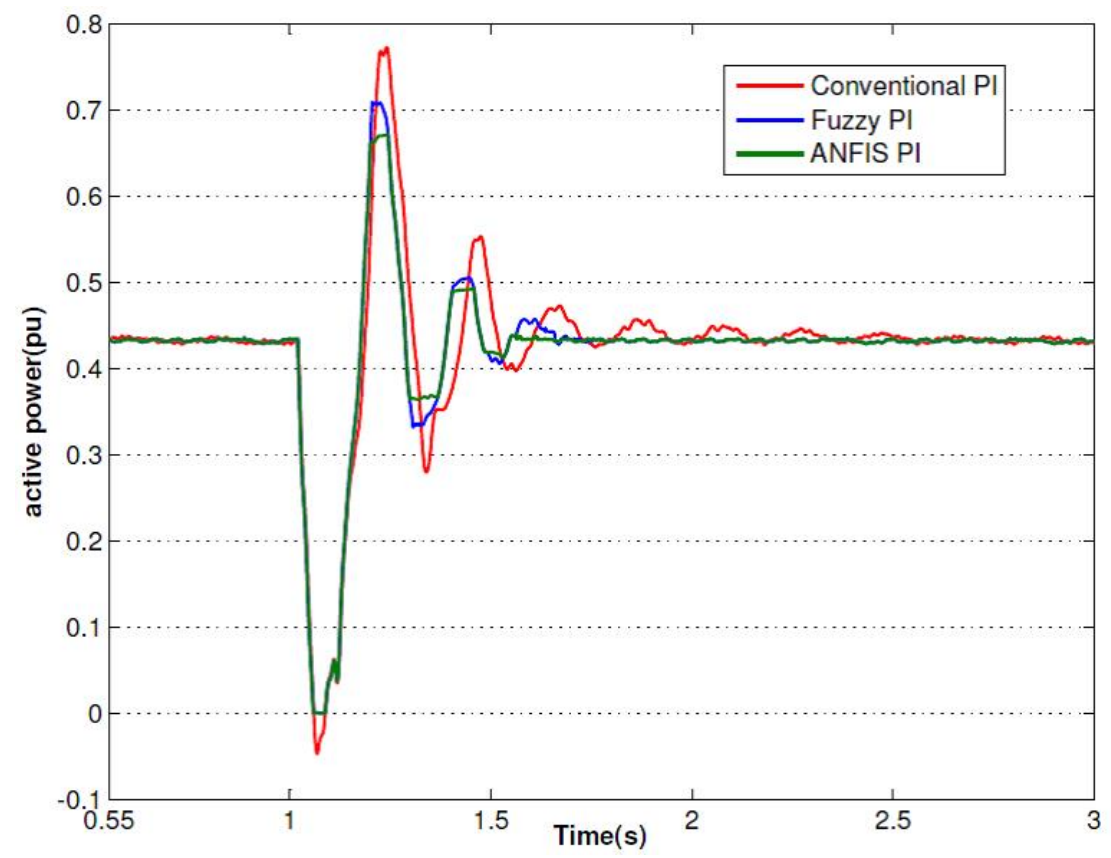

(b)

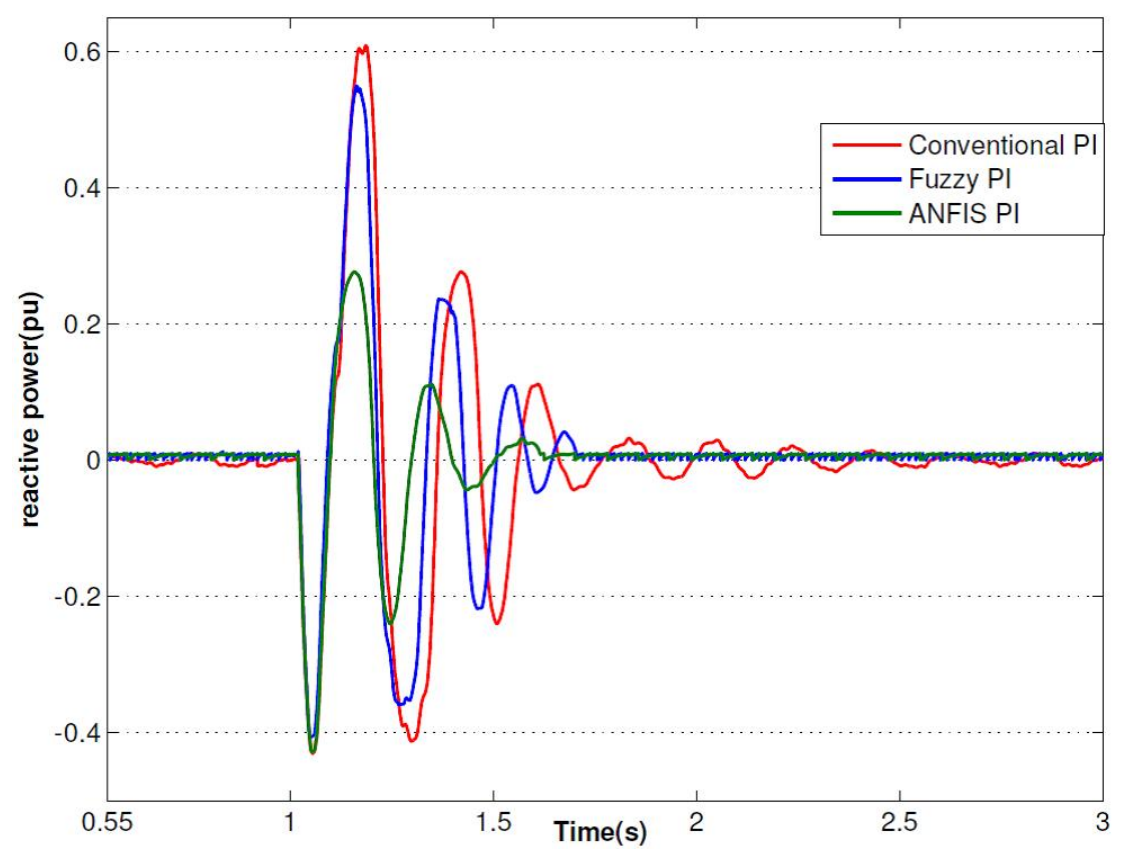

Figure 8. (a) Active power (b) reactive power at rectifier AC bus for a 5 cycle three phase fault on inverter side AC bus. 
(a)

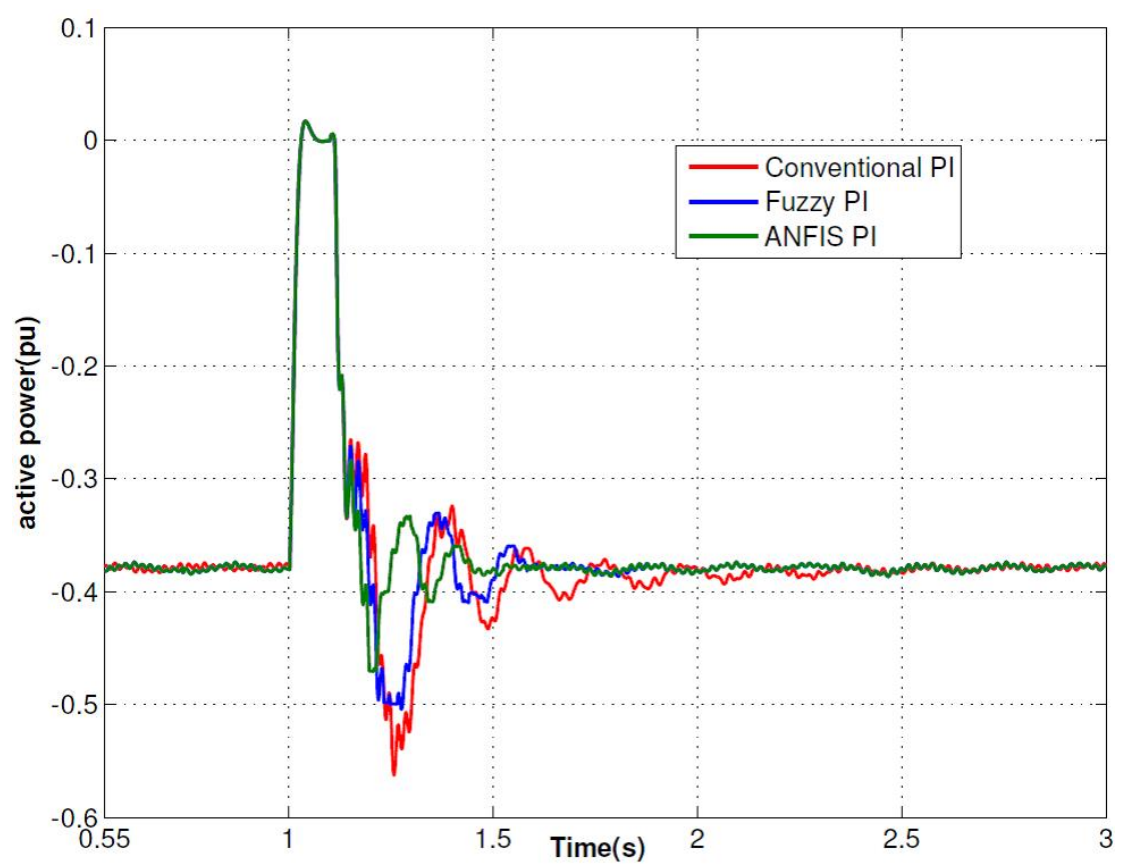

(b)

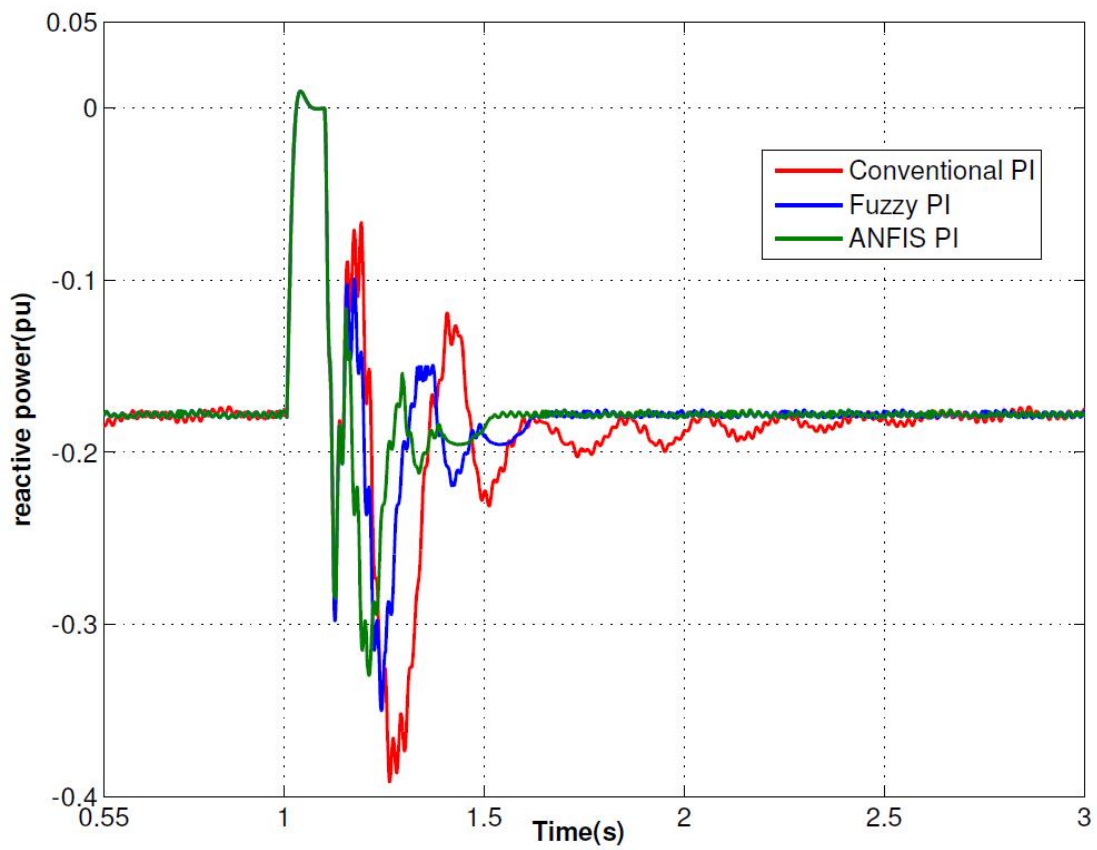

Figure 9. (a) Active power (b) reactive power at inverter AC bus for a 5 cycle three phase fault on inverter side AC bus. 
with ANFIS technology offers better damping performance under different perturbations.

5. Hence, it is recommended that the proposed system offer better solutions in the future in order to provide a reliable, convenient and cost-effective energy to customers.

\section{References}

[1] Asplund G., Eriksson K., Svensson K., HVDC Light-DC transmission based on voltage-sourced converters, ABB Rev. 1, 1998, 4-9

[2] Ravemark D., Normark B., Light and invisible; Underground transmission with HVDC Light ${ }^{\circledR}, A B B$, ABB Revi. 4, 2005, 25-29

[3] Flourentzou N., Agelidis V., Demetriades G., VSCbased HVDC power transmission systems: An overview, IEEE Transactions on Power Electronics 24, 2009, 592-602

[4] Ajay kumar M., Archana K. U., Srikanth N. V., HVDC Light Systems: An overview, International Review on Modelling and Simulations 5, 2012, 1951-1959

[5] Jiang H., Ekstrom A., Multiterminal HVDC systems in urban areas of large cities, IEEE Transactions on Power Delivery 13, 1998, 1278-1284

[6] Bresesti P., Kling W. L., Hendriks R. L., Vailati R., HVDC connection of offshore wind farms to the transmission system, IEEE Trans. Energy Convers. 22, 2007, 37-43

[7] Kirby N. M., Xu L., Luckett M. and Siepmann W., HVDC transmission for large offshore wind farms, IEEE Trans. On Power Eng. Journal 16, 2002, 135141

[8] Guo-Jie Li, SiyeRuan, Lin Peng et al., A novel nonlinear control for stability improvement in HVDC Light system, IEEE Conf. on Power Engineering Society, Beijing 1, 2005, 837-845

[9] Cuiqing Du, Evert Agneholm, Gustaf Olsson, Use of VSC-HVDC for Industrial Systems Having Onsite Generation With Frequency Control, IEEE Transactions on Power Delivery 23, 2008, 2233-2240

[10] Xiaofan Fu, Dessaint L.-A, Gagnon R., Keliang Zhou, Ming Cheng, Modeling and simulation of VSC-HVDC with current deadbeat control, proceedings of IEEE International Conference on Electrical Machines and Systems (ICEMS) 2011, 1-6

[11] Durrant M., Werner H., Abbott K., Model of a VSC HVDC terminal attached to a weak AC system, Proceedings of IEEE Conf. Control Appl. 2003, Istanbul, Turkey, 178-182

[12] Shuhui Li, Timothy A. Haskew, Ling Xu, Control of HVDC Light System Using Conventional and Direct Current Vector Control Approaches, IEEE Transactions on Power Electronics 25, 2010, 31063118

[13] Ajay kumar M., Srikanth N. V., Performance of SVPWM based vector controlled HVDC Light transmission system under balanced fault condition, proceedings of IEEE power and energy conference at Illinois (Feb. 22-23, 2013), 2013, 194-199

[14] Moharana. A, Samarabandu. J, Varma, R. K., Fuzzy supervised $\mathrm{PI}$ controller for VSC HVDC system connected to Induction Generator based wind farm, proceedings of IEEE Electrical Power and Energy Conference (EPEC), 2011, 432-437

[15] Daneshpooy A., Gole A. M., Chapman D. G, Davies J. B., Fuzzy logic control for HVDC transmission, IEEE Transactions on Power Delivery 12, 1997, 1690-1697

[16] Zhang Yun, Zhou Quan, Sun Caixin, Lei Shaolan, Liu Yuming, Song Yang, RBF Neural Network and ANFIS-Based Short-Term Load Forecasting Approach in Real-Time Price Environment, IEEE Transactions on power systems 23, 2008, 853-857

[17] Jyh-Shing Roger Jang, ANFIS: Adaptive-network based fuzzy inference system, IEEE transactions on systems, man, and cybernetics 23, 1993, 665-685

[18] Li Wang, Dinh-Nhon Truong, Stability enhancement of a power system with a PMSG-based and a DFIG-based offshore wind farm using a SVC with an adaptive-network-based fuzzy inference system, IEEE transactions on industrial electronics 60, 2013, 2799-2807

[19] Ajay kumar M., Srikanth N. V., Dynamic Performance of an adaptive neuro fuzzy inference system based vector controlled HVDC Light transmission system, proceedings of Fifth International Conference on Power and Energy Systems (ICPS), 2013, 38-42 